\title{
Physiological responses during exposure to carbon dioxide and bioeffluents at levels typically occurring indoors
}

Zhang, X.; Wargocki, Pawel; Lian, Z.

Published in:

Indoor Air

Link to article, DOI:

10.1111/ina.12286

Publication date:

2017

Document Version

Publisher's PDF, also known as Version of record

Link back to DTU Orbit

Citation (APA):

Zhang, X., Wargocki, P., \& Lian, Z. (2017). Physiological responses during exposure to carbon dioxide and bioeffluents at levels typically occurring indoors. Indoor Air, 27(1), 65-77. https://doi.org/10.1111/ina.12286

\section{General rights}

Copyright and moral rights for the publications made accessible in the public portal are retained by the authors and/or other copyright owners and it is a condition of accessing publications that users recognise and abide by the legal requirements associated with these rights.

- Users may download and print one copy of any publication from the public portal for the purpose of private study or research.

- You may not further distribute the material or use it for any profit-making activity or commercial gain

- You may freely distribute the URL identifying the publication in the public portal 


\section{Physiological responses during exposure to carbon dioxide and bioeffluents at levels typically occurring indoors}

\begin{abstract}
Twenty-five subjects were exposed to different levels of carbon dioxide $\left(\mathrm{CO}_{2}\right)$ and bioeffluents. The ventilation rate was set high enough to create a reference condition of $500 \mathrm{ppm} \mathrm{CO}_{2}$ with subjects present; additional $\mathrm{CO}_{2}$ was then added to supply air to reach levels of 1000 or $3000 \mathrm{ppm}$, or the ventilation rate was reduced to allow metabolically generated $\mathrm{CO}_{2}$ to reach the same two levels (bioeffluents increased as well). Heart rate, blood pressure, end-tidal $\mathrm{CO}_{2}$ $\left(\mathrm{ETCO}_{2}\right)$, oxygen saturation of blood $\left(\mathrm{SPO}_{2}\right)$, respiration rate, nasal peak flow, and forced expiration were monitored, and the levels of salivary $\alpha$-amylase and cortisol were analyzed. The subjects performed a number of mental tasks during exposures and assessed their levels of comfort and the intensity of their acute health symptoms. During exposure to $\mathrm{CO}_{2}$ at 3000 ppm, when $\mathrm{CO}_{2}$ was added or ventilation was restricted, $\mathrm{ETCO}_{2}$ increased more and heart rate decreased less than the changes that occurred in the reference condition. Exposure to bioeffluents, when metabolically generated $\mathrm{CO}_{2}$ was at $3000 \mathrm{ppm}$, significantly increased diastolic blood pressure and salivary $\alpha$-amylase level compared with pre-exposure levels, and reduced the performance of a cue-utilization test: These effects may suggest higher arousal/stress. A model is proposed describing how mental performance is affected by exposure to bioeffluents.
\end{abstract}

\author{
X. Zhang ${ }^{1,2}$, P. Wargocki ${ }^{2}$, Z. Lian $^{1}$ \\ ${ }^{1}$ School of Naval Architecture, Ocean and Civil \\ Engineering, Shanghai Jiao Tong University, Shanghai, \\ China, ${ }^{2}$ International Centre for Indoor Environment and \\ Energy, Technical University of Denmark, Kongens \\ Lyngby, Denmark \\ Key words: Carbon dioxide; Human bioeffluents; Acute \\ health symptoms; Mental performance; Physiological \\ responses; Mechanism. \\ X. Zhang \\ School of Naval Architecture, Ocean and Civil \\ Engineering \\ Shanghai Jiao Tong University \\ Shanghai, 200240, China \\ Tel.: +86 18801903326 \\ Fax: $+86(021) 34204263$ \\ e-mail: xjzhanger@163.com \\ Received for review 28 September 2015. Accepted for \\ publication 3 February 2016.
}

\section{Practical Implications}

The present results suggest potential pathways by which exposures to $\mathrm{CO}_{2}$ and bioeffluents at levels typically occurring indoors may evoke physiological responses in humans. These responses may have consequences for health and mental performance. Better understanding of the mechanism underlying the effects of indoor exposures and physiological responses would make it easier to recommend appropriate mitigation measures and to identify metrics/outcomes that could be used to verify their efficiency.

\section{Introduction}

Carbon dioxide $\left(\mathrm{CO}_{2}\right)$ is one of the components of the Earth's atmosphere. It is also a major product of human metabolism. The indoor $\mathrm{CO}_{2}$ concentration depends mainly on human occupancy (source strength) and on the outdoor air supply rate (dilution). They are typically below $2000-2500 \mathrm{ppm}$, but can reach as high as 4000-5000 ppm (e.g., Bekö et al., 2010; Menå and Larsen, 2010; Myhrvold et al., 1996; Shaughnessy et al., 2006; Stricker et al., 1997); that is, they can be up to one-order of magnitude higher than outdoor levels, which are now on average about $400 \mathrm{ppm}$. Elevated $\mathrm{CO}_{2}$ levels indoors are always accompanied by the other pollutants that are emitted either by humans (human bioeffluents) or by buildings. Indoor levels of $\mathrm{CO}_{2}$ are an order of magnitude lower than the concentration of $\mathrm{CO}_{2}$ in exhaled air, which is 40000 $50000 \mathrm{ppm}$.

There have been many studies of the health consequences of exposure to elevated levels of pure $\mathrm{CO}_{2}$ (Table 1). $\quad \mathrm{CO}_{2}$ concentrations from 50000 to 150000 ppm (i.e., three times higher than in exhaled breath) were examined during relatively short exposures lasting 10-20 min (Bailey et al., 2005; Diaper et al., 2012; Maresh et al., 1997; Sayers et al., 1987; Sechzer et al., 1960; Woods et al., 1988). Changes in the respiratory system were observed to occur, including an increase in respiration rate, minute ventilation rate, and end-tidal $\mathrm{CO}_{2}\left(\mathrm{ETCO}_{2}\right)$. Changes in the 
cardiovascular system were also observed, as manifested by increased heart rate and blood pressure. Although important and suggestive of some hazard for health, these effects occurred at $\mathrm{CO}_{2}$ concentrations that were an order of magnitude higher than typical indoor levels, as these rarely exceed 3000-5000 ppm, and also exceeded the 8-h averaged occupational exposure limit of 5000 ppm (ACGIH, 2011).

Other studies have examined the health effects of long-term exposures (days to months) to $\mathrm{CO}_{2}$ at lower levels ranging from $5000 \mathrm{ppm}$ to $15000 \mathrm{ppm}$ (Table 1). These exposures also evoked physiological responses, such as increased respiratory minute ventilation rate, $\mathrm{ETCO}_{2}$ (Schaefer et al., 1963), and cerebral blood flow (Sliwka et al., 1998), and lowered $\mathrm{pH}$ in blood (Gortner et al., 1971). Subjects exposed to these levels reported increased headache (James et al., 2011; Law et al., 2014; Sliwka et al., 1998). These studies were performed in special environments, such as in spacecraft and submarines. Unlike the studies mentioned above, in which subjects were exposed to pure $\mathrm{CO}_{2}$ at levels higher than $20000 \mathrm{ppm}$, studies in these special environments allowed metabolically generated $\mathrm{CO}_{2}$ to increase by restricting the outdoor air supply rate. As a result, other pollutants, mainly human bioeffluents but probably also pollutants from other indoor sources, were elevated as well. The observed physiological changes and subjective responses cannot therefore be attributed only to $\mathrm{CO}_{2}$ but may be due to elevated levels of the other pollutants.
A recent study by Vehviläinen et al. (2016) examined the effects of exposure to high indoor $\mathrm{CO}_{2}$ concentrations in a conference room. Two exposure conditions were created by operating or idling the ventilation system, resulting in average $\mathrm{CO}_{2}$ levels of $906 \mathrm{ppm}$ or $2756 \mathrm{ppm}$. Four male subjects were exposed three times to each condition, each time for $4 \mathrm{~h}$. Increased sleepiness, higher $\mathrm{CO}_{2}$ concentrations in tissues, changes in heart rate variability, and increased peripheral blood circulation resistance were observed at the higher $\mathrm{CO}_{2}$ levels. These effects cannot be attributed solely to elevated $\mathrm{CO}_{2}$ because other pollutants including other bioeffluents, organic compounds, and fine particles also increased significantly, as did the temperature and relative humidity, when the outdoor air supply rate was decreased.

Three recent experiments investigated exposures to pure $\mathrm{CO}_{2}$ at levels typically occurring in indoor environments. Kajtár and Herczeg (2012) exposed 10 subjects for 2-3 h to levels up to $3000 \mathrm{ppm}$, Satish et al. (2012) exposed 22 subjects to levels up to $2500 \mathrm{ppm}$, and Allen et al. (2015) exposed 24 subjects for $8 \mathrm{~h}$ to levels up to $1400 \mathrm{ppm}$. Kajtár and Herczeg (2012) observed an increase in the diastolic blood pressure (which was reported to occur at exposures to 75000 ppm by Diaper et al. (2012)) and a decrease in the mid-frequency components of heart rate variability. They also reported that the performance of a proofreading test was lower when the $\mathrm{CO}_{2}$ level increased. Subjects reported fatigue and a decrease in

Table 1 Summary of studies examining physiological responses to elevated levels of $\mathrm{CO}_{2}(<14 \%), 1 \%=10000 \mathrm{ppm}$

\begin{tabular}{|c|c|c|c|c|c|c|}
\hline Effects & $\mathrm{CO}_{2}(\%)^{*}$ & Duration & Venue & $\begin{array}{l}\text { Number of } \\
\text { subjects }\end{array}$ & Effects & Reference \\
\hline \multirow[t]{6}{*}{ Cardiovascular } & $7-14$ & $10-20 \mathrm{~min}$ & Inhalation & 12 & Increased heart rate and blood pressure & Sechzer et al. (1960) \\
\hline & $5-7.5$ & $15-20 \mathrm{~min}$ & Inhalation & $33 / 20 / 20$ & Increased heart rate and blood pressure & $\begin{array}{l}\text { Woods et al. (1988); Bailey et al. (2005); } \\
\text { Diaper et al. (2012) }\end{array}$ \\
\hline & $0.65-1.2^{*}$ & 42 days & Submarine & 12 & Lowered pH of blood & Gortner et al. (1971) \\
\hline & 0.5 & $2-3 \mathrm{~h}$ & Chamber & 10 & Increased diastolic blood pressure & Kajtár and Herczeg (2012) \\
\hline & 0.3 & $2-3 \mathrm{~h}$ & Chamber & 10 & $\begin{array}{l}\text { Reduced components of middle frequency of } \\
\text { heart rate variability }\end{array}$ & Kajtár and Herczeg (2012) \\
\hline & $0.09-0.28^{*}$ & $3 \mathrm{~h}$ & Office & 4 & $\begin{array}{l}\text { Change in heart rate variability; Increased peripheral } \\
\text { blood circulation resistance }\end{array}$ & Vehviläinen et al. (2016) \\
\hline \multirow[t]{5}{*}{ Respiratory } & $7-14$ & 10-20 min & Inhalation & 12 & Increased respiratory minute ventilation rate & Sechzer et al. (1960) \\
\hline & $7.5-8$ & $15 \mathrm{~min}$ & Inhalation & $32 / 20$ & Increased $\mathrm{ETCO}_{2}$ and respiration rate & Maresh et al. (1997); Bailey et al. (2005) \\
\hline & $1.5^{*}$ & 42 days & Submarine & 21 & Increased respiratory minute ventilation rate and $\mathrm{ETCO}_{2}$ & Schaefer et al. (1963) \\
\hline & $0.3^{*}$ & 1 night & Closed bedroom & 22 & No effects on respiration rate & Stricker et al. (1997) \\
\hline & $0.09-0.28^{*}$ & $3 \mathrm{~h}$ & Office & 4 & Increased transcutaneous $\mathrm{CO}_{2}$ concentration & Vehviläinen et al. (2016) \\
\hline \multirow[t]{6}{*}{$\begin{array}{l}\text { Central nervous } \\
\text { system }\end{array}$} & $5-7.5$ & 15-20 min & Inhalation & $10 / 33 / 20 / 20$ & $\begin{array}{l}\text { Subjectively assessed anxiety, headache and } \\
\text { irritability increased }\end{array}$ & $\begin{array}{l}\text { Sayers et al. (1987); Woods et al. (1988); } \\
\text { Bailey et al. (2005); Diaper et al. (2012) }\end{array}$ \\
\hline & $1.2^{*}$ & 23 days & - & 4 & $\begin{array}{l}\text { Subjectively assessed headache increased; cerebral } \\
\text { blood flow first increased then returned to original level }\end{array}$ & Sliwka et al. (1998) \\
\hline & $0.5-0.6^{*}$ & 100 days & $\begin{array}{l}\text { International } \\
\text { space station }\end{array}$ & $-/ 49$ & Subjectively assessed headache increased & James et al. (2011); Law et al. (2014) \\
\hline & $0.3^{*}$ & 1 night & Closed bedroom & 22 & $\begin{array}{l}\text { No effects on subjectively assessed headache, } \\
\text { fatigue, and concentrate attention }\end{array}$ & Stricker et al. (1997) \\
\hline & 0.3 & $2-3 \mathrm{~h}$ & Chamber & 10 & $\begin{array}{l}\text { Subjectively assessed fatigue increased; } \\
\text { concentrate attention reduced }\end{array}$ & Kajtár and Herczeg (2012) \\
\hline & $0.09-0.28^{*}$ & $3 \mathrm{~h}$ & Office & 4 & Subjectively reported sleepiness increased & Vehviläinen et al. (2016) \\
\hline
\end{tabular}

*In addition to elevated $\mathrm{CO}_{2}$, other pollutants, such as human bioeffluents were present. 
well-being and the ability to concentrate. In the study by Satish et al. (2012), exposure to artificially elevated $\mathrm{CO}_{2}$ at $1000 \mathrm{ppm}$ and $2500 \mathrm{ppm}$ caused a systematic decrease in the performance of subjects taking a battery of tests measuring decision-making performance under a high cognitive load. In the study by Allen et al. (2015), the same tests as used by Satish et al. (2012) were performed by subjects. Their results exhibited also similar pattern as in the study by Satish et al. (2012): Several cognitive function domains depicting the ability for making decisions decreased significantly when $\mathrm{CO}_{2}$ levels were ca. $945 \mathrm{ppm}$ and $1400 \mathrm{ppm}$ compared with $\mathrm{CO}_{2}$ levels of $550 \mathrm{ppm}$. Neither the study by Satish et al. (2012) nor the study by Allen et al. (2015) reported other measurements, such as physiological measurements, which makes it difficult to determine whether the observed effects are attributable to changes in physiological response, although such circumstance cannot be completely ruled out.

The results of Kajtár and Herczeg (2012), Satish et al. (2012), and Allen et al. (2015) suggest that $\mathrm{CO}_{2}$ at levels normally measured indoors may have adverse effects on humans, which means that $\mathrm{CO}_{2}$ should be considered as a pollutant and not simply as a surrogate for other bioeffluents and indoor pollutants as recommended by Pettenkofer (1858) and accepted ever since. If true, this would have consequences for ventilation requirements and the principles by which they are determined, but only in cases where work performance is used as the outcome that determines the ventilation requirement, because this was the outcome affected by $\mathrm{CO}_{2}$ in the mentioned studies.

It is clear from the published literature that $\mathrm{CO}_{2}$ is correlated with acute health symptoms, perceived air quality (PAQ) and cognitive performance, and with a number of physiological responses (e.g., Apte et al., 2000; Erdmann et al., 2002; Haverinen-Shaughnessy et al., 2011; Law et al., 2010; Mendell et al., 2013; Seppänen et al., 1999), although in these studies $\mathrm{CO}_{2}$ was never considered to be a pollutant itself but simply an indicator of exposure to other pollutants due to insufficient dilution and removal by ventilation.

Some studies have documented physiological responses to human bioeffluents. Most of the available data regarding the effects of human bioeffluents are on sensory perceptions (e.g., Fanger, 1988) or acute health symptoms. A recent study by Maddalena et al. (2015) examined the effects of bioeffluents on different human outcomes by separating the exposure of subjects to human bioeffluents from exposures to emissions from building materials. They showed that when 16 subjects were exposed for $4 \mathrm{~h}$ to $1800 \mathrm{ppm} \mathrm{CO}_{2}$ with bioeffluents, there was a significant decrease in their decisionmaking performance in comparison with $900 \mathrm{ppm}$, but there were no differences between these two exposures in terms of their subjectively reported perception of air quality or their acute health symptoms.
This study provides new evidence on subjective perceptions, cognitive performance, and physiological responses during exposure to $\mathrm{CO}_{2}$. Another paper describing the other results from the same series of experiments (Zhang et al., 2016) showed that moderate concentrations of bioeffluents but not pure $\mathrm{CO}_{2}$ reduced PAQ, increased intensity of self-evaluated acute health symptoms and had measurable effects on cognitive performance that were not always negative. The particular focus of this paper is to present the results of physiological responses in an attempt to examine the underlying mechanisms mediating subjective responses and affecting cognitive performance.

\section{Methods}

Approach

Twenty-five subjects were exposed for 255 min to different levels of $\mathrm{CO}_{2}$ and human bioeffluents. The exposures took place in a stainless steel climate chamber and followed a Latin square design that was balanced for order of presentation. During the exposures, changes in the respiratory and cardiovascular systems were measured. Stress biomarkers were sampled and analyzed. Cognitive performance was examined using multiple tests. Subjective ratings of comfort, acute health symptoms, and levels of effort and performance were obtained. The full details of the experimental procedures and the approach have been described by Zhang et al. (2016), while this paper reports the physiological measurements that were taken in parallel.

\section{Facilities}

The experiment was carried out in a $3.6 \times 2.5 \times 2.5 \mathrm{~m}$ low-emitting stainless steel chamber (volume of $30 \mathrm{~m}^{3}$ with recirculation ducts), which has been described in detail by Albrechtsen (1988) and by Zhang et al. (2016). The chamber has its own system for supplying and conditioning outdoor air. The air in the chamber is well mixed throughout the entire volume. This was verified by measurements prior to the present experiment. The chamber was additionally thoroughly cleaned and 'baked' immediately prior to the present experiments to ensure that the background pollution level was low. New G3/F7 particle filters were installed in the supply ducts prior to the experiments. No other filters or air cleaners were installed. No scrubbing of the air was performed in the climate chamber in any of the exposure conditions studied. No chemical measurements were made prior to the present experiments to prove that the actions described above had removed any residual pollution or that the background pollution levels in the chamber were negligible. Similar actions taken in previous studies were shown to be sufficient to achieve the goal of reducing the background pollution 
(e.g., Darling et al., 2012; Fang et al., 1998a,b; Kjærgaard et al., 1999). Sensory assessments made by the subjects during the present experiments showed that in the reference condition termed as B500 (coding of exposures is described later) the percentage dissatisfied with air quality was less than $20 \%$ (Zhang et al., 2016). These results provide attest that the background pollution level was truly low. It should additionally be noted that addition of pure $\mathrm{CO}_{2}$ in exposures $\mathrm{P} 1000$ and P3000 did not increase the percentage dissatisfied with the air quality compared with the reference condition (termed B500) (Zhang et al., 2016).

There were six workstations in the chamber for five subjects and the experimenter, who remained in the chamber throughout each exposure, each workstation consisting of a table, a chair, a laptop PC, and a desk lamp.

\section{Subjects}

Twenty-five subjects were recruited for the experiment by means of advertisements distributed on the university campus (Table 2). All of the subjects were Danish and could speak English fluently. They were paid DKK 130.45 per hour for taking part in the experiments. All subjects gave written and informed consent to their participation in the experiments. This experiment intended to examine responses of randomly selected healthy young college-age adults (students), but this appeared to be difficult to achieve. Consequently, eight atopic subjects were recruited as well. By chance, the ratio of atopic subjects to all subjects included was $32 \%$, which is close to the prevalence of atopic subjects in the general population in Denmark where it is at the level of 24\% (Masoli et al., 2004). Additionally, twelve recruited subjects (just below 50\%) reported that they considered themselves to be sensitive to air quality (three of them were atopic subjects). Whether they were truly sensitive to air quality was not verified by any objective methods or sensory tests. Eight other subjects recruited for these experiments indicated that they considered themselves to be sensitive to heat, cold, light, and/or noise.

\section{Experimental conditions}

Five exposures were examined: a reference exposure with $\mathrm{CO}_{2}$ at $500 \mathrm{ppm}$ (referred to as B500), exposure to $\mathrm{CO}_{2}$ at $1000 \mathrm{ppm}$ and $3000 \mathrm{ppm}$, achieved by adding $\mathrm{CO}_{2}$ to the supply air (referred to as P1000 and $\mathrm{P} 3000$, respectively), and exposure to metabolically generated $\mathrm{CO}_{2}$ at $1000 \mathrm{ppm}$ and $3000 \mathrm{ppm}$, achieved by restricting the ventilation rate to allow the $\mathrm{CO}_{2}$ generated by human subjects staying in the chamber to increase to the same two levels as in P1000 and P3000, respectively (referred to as M1000 and M3000);
Table 2 Personal characteristics of the subjects participating in the experiment collected via questionnaire distributed to subjects upon recruitment

\begin{tabular}{lc}
\hline Characteristic & Description (mean \pm s.d.) \\
\hline Total number of subjects & 25 (10 male, 15 female) \\
Age (years) & $23 \pm 2$ \\
Height (cm) & $173 \pm 11$ \\
Weight (kg) & $74.9 \pm 21.8$ \\
Occupation & Students \\
Number of smokers & 0 \\
Number of atopic subjects ${ }^{\text {a,b }}$ & 8 \\
Number of subjects reporting themselves & 12 \\
$\quad$ more sensitive to indoor air quality & \\
Number of subjects reporting themselves & 8 \\
$\quad$ more sensitive to heat/cold/light/noise & \\
Number of subjects suffering from chronic disease & 0 \\
\hline
\end{tabular}

${ }^{a}$ One subject with asthma, allergy, and eczema ever, one with asthma and allergy, three with allergy only, two with hay fever ever only, and one with eczema ever only; none was symptomatic during the experiments.

${ }^{b}$ Among the eight atopic subjects, three reported that they considered themselves to be sensitive to indoor air quality.

together with $\mathrm{CO}_{2}$, the bioeffluent levels increased as well.

The difference between exposure B500 and exposures $\mathrm{P} 1000$ and $\mathrm{P} 3000$ was the concentration of $\mathrm{CO}_{2}$. In these three exposures, the outdoor air supply rate was set high enough to reduce the bioeffluents from the six persons staying in the chamber during experiments to a very low level, and to keep the background level of $\mathrm{CO}_{2}$ at the concentration of $500 \mathrm{ppm}$.

The difference between exposure B500 and exposures $\mathrm{M} 1000$ and $\mathrm{M} 3000$ was the concentration of $\mathrm{CO}_{2}$ and bioeffluents; the higher levels of $\mathrm{CO}_{2}$ and bioeffluents were obtained in the latter two exposures by restricting outdoor air supply rate.

The difference between P1000 and M1000 and between P3000 and M3000 was the level of bioeffluents; the higher concentrations of bioeffluents were attained in $\mathrm{M}$-exposures; $\mathrm{CO}_{2}$ concentration was similar for respective pairs but in the P-exposures $\mathrm{CO}_{2}$ was artificially added to the chamber, whereas in the $\mathrm{M}$ exposures it was generated by the subjects as a result of metabolic processes.

Real-time $\mathrm{CO}_{2}$ measurements were made to ensure that the intended concentrations of $\mathrm{CO}_{2}$ were reached (Table 3). Temperature, relative humidity, and noise level were kept constant at $24^{\circ} \mathrm{C}, 30 \%$, and $45 \mathrm{~dB}(\mathrm{~A})$ during the exposures.

\section{Measurements}

Measurements of physiological parameters included continuous measurement of heart rate, repeated measurements of blood pressure and obstruction of the upper respiratory tract immediately prior to and after the exposure, four repeated measurements of breathing rate overlapping the period when subjects were typing the text, and five repeated measurements of $\mathrm{ETCO}_{2}$ 
and oxygen saturation of blood $\left(\mathrm{SPO}_{2}\right)$ before the exposure and every one hour during the exposure, when subjects were taking a short pause before starting on the next task (Figure 1). $\mathrm{ETCO}_{2}$ and $\mathrm{SPO}_{2}$ were measured simultaneously using a Lifesense Monitor by MedAir AB. The measurable range of $\mathrm{ETCO}_{2}$ was 0 $9.9 \mathrm{kPa}$ and the accuracy was $\pm 0.2 \mathrm{kPa}+6 \%$ of reading according to the manufacturer's specifications; the measurable range of $\mathrm{SPO}_{2}$ was $0-100 \%$ and the accuracy was $\pm 2 \%$. ETCO 2 and $\mathrm{SPO}_{2}$ were measured for about $60 \mathrm{~s}$, and the data between the 15th and 45th second were averaged and used for analyzing any changes in their levels between exposure conditions.

Samples of saliva were collected from subjects (by asking them to drool) immediately before and after the exposure to analyze changes in two stress biomarkers: $\alpha$-amylase and cortisol. Immediately after collection, the samples were centrifuged for $15 \mathrm{~min}$ at $3000 \mathrm{rpm}$, then placed in a freezer at $-20^{\circ} \mathrm{C}$. One hour later, the samples were again centrifuged and then stored in the freezer until analysis. Saliva samples were analyzed by the external laboratory. Amylase assay was performed with Integra 400 plus (Roche Diagnostics Ltd., Basel, Switzerland). Amylase samples were diluted 201 times before analysis to reduce the amylase level in saliva, as the applied method is not applicable at such high levels as those occurring in saliva. After dilution, the amylase level was determined and then the dilution factor applied to estimate the actual concentration in saliva. Repeated analyses on the same samples using the dilution method described above returned similar results. The detection limit was $3 \mathrm{U} / 1(0.003 \mathrm{U} / \mathrm{ml})$ while the analytical error of measurement was $5.7 \%$. Cortisol assay was performed with Cobas 6000/e601 (Roche Diagnostics Ltd.). The detection limit was $0.018 \mu \mathrm{g} / \mathrm{dl}$

Table 3 Designed and measured $\mathrm{CO}_{2}$ levels during different exposures

\begin{tabular}{|c|c|c|c|c|c|}
\hline Condition & B500 & P1000 & P3000 & M1000 & M3000 \\
\hline $\begin{array}{l}\text { Outdoor air } \\
\text { supply rate } \\
\text { to the chamber } \\
\left(\mathrm{m}^{3} / \mathrm{h}\right) /(\mathrm{l} / \mathrm{s} \\
\text { per person) }\end{array}$ & $720 / 33.3$ & $720 / 33.3$ & $720 / 33.3$ & $155 / 7.2$ & $38 / 1.8$ \\
\hline $\begin{array}{l}\mathrm{CO}_{2} \text { transported with } \\
\text { outdoor air (I/min) }\end{array}$ & 4.2 & 4.2 & 4.2 & 0.9 & 0.2 \\
\hline $\begin{array}{l}\text { Pure } \mathrm{CO}_{2} \text { dosed from } \\
\text { cylinders }(1 / \mathrm{min})\end{array}$ & - & 6 & 30 & - & - \\
\hline $\begin{array}{l}\text { Metabolic } \\
\mathrm{CO}_{2} \text { generated } \\
\text { by people in } \\
\text { the chamber }(1 / \mathrm{min})\end{array}$ & 1.9 & 1.9 & 1.9 & 1.9 & 1.9 \\
\hline $\begin{array}{l}\text { Designed } \mathrm{CO}_{2} \\
\text { level in the } \\
\text { chamber (outdoor } \\
\text { level at } 350 \mathrm{ppm} \text { ) }\end{array}$ & 500 & 1000 & 3000 & 1000 & 3000 \\
\hline $\begin{array}{l}\text { Measured } \mathrm{CO}_{2} \text { level } \\
\text { (mean } \pm \text { s.e., ppm) }\end{array}$ & $435 \pm 37$ & $1083 \pm 37$ & $3004 \pm 47$ & $1124 \pm 75$ & $3192 \pm 343$ \\
\hline
\end{tabular}

$(0.4968 \mathrm{nmol} / \mathrm{l})$, while the analytical error of the measurement was $11.7 \%$.

Heart rate was measured with a Suunto dual comfort belt (SS014543000, Suunto Oy, Vantaa, Finland), and data recorded during periods of text typing, addition, and neurobehavioral tests (Figure 1) were used to examine any differences between exposures. Blood pressure was measured using a Beurer BM 35. Obstruction of the respiratory tract was examined by means of a nasal peak flow test, using portable inspiratory flow meter with a range of $15 \sim 1201 / \mathrm{min}$ by Clement Clarke International Ltd. (Harlow, UK) and with a Spirometry test using a Vitalograph Spirotrac model 7000. Spirometry tests are widely used to measure pulmonary function, especially the amount (volume) and the speed (flow) of air that can be inhaled and exhaled. A variety of parameters were calculated in the present measurement, including forced vital capacity (FVC), forced expiratory volume in $1 \mathrm{~s}\left(\mathrm{FEV}_{1}\right), \mathrm{FEV} 1 / \mathrm{FVC}$ ratio $\left(\mathrm{FEV}_{1} \mathrm{FVC}\right)$, peak expiratory flow (PEF), and maximal mid expiratory flow: the mean forced expiratory flow in the time interval between $25 \%$ and $75 \%$ of the FVC $\left(\mathrm{FEF}_{25-75}\right)$. The breathing rate was measured with an apparatus developed by the experimental team for the purpose of this study. It consisted of a thermistor Pt100 with a range of $-50 \sim 500^{\circ} \mathrm{C}$ and a response time of 0.1 s (RS Components Ltd., Corby, UK), a normal headset and an Agilent 34970A data acquisition unit. The thermistor was used to continuously measure the temperature of the exhaled air. It was attached to a headset worn by each subject and was situated close to one nostril, where the fluctuation of the temperature of respired air was large. Breathing rate was estimated by observing the change in temperature. This was performed by counting the number of peaks per minute in the temperature fluctuation.

$\mathrm{CO}_{2}$ concentration, air temperature, and relative humidity were monitored continuously at the sitting height of the subjects using two calibrated monitors and were recorded every five minutes by a data logger. Ozone levels in the chamber were monitored continuously with a calibrated ozone monitor. Spot measurements of light and noise were carried out once at the end of the experiment. Subjective ratings were collected three to four times (Figure 1); they included subjective ratings of the indoor environment and of any acute health symptoms and self-estimates of the subjects' performance of the cognitive tests. Cognitive performance was examined by means of a test battery (Figure 1) that included tasks resembling different aspects of office work (proofreading, addition, subtraction, and text typing), neurobehavioral tests (redirection, grammatical reasoning, digit span, Stroop with and without feedback on errors), a Tsai-Partington test, and a d2 search test. Details of these measurements have been presented by Zhang et al. (2016). 


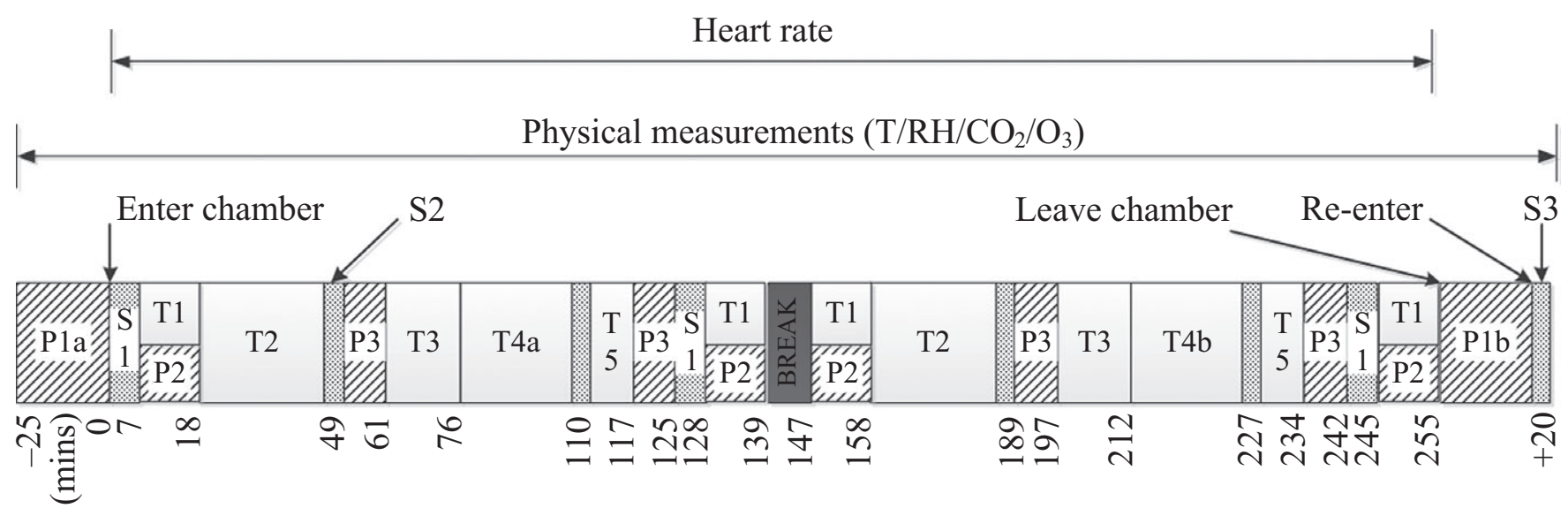

P denotes physiological measurements: $\mathrm{P} 1 \mathrm{a}$ includes saliva sampling, blood pressure, nasal peak flow, forced expiration, $\mathrm{ETCO}_{2}$ and $\mathrm{SPO}_{2}$, while $\mathrm{P} 1 \mathrm{~b}$ without $\mathrm{ETCO}_{2}$ and $\mathrm{SPO}_{2} ; \mathrm{P} 2$ indicates respiration rate; $\mathrm{P} 3$ indicates $\mathrm{ETCO}_{2}$ and $\mathrm{SPO}_{2}$

$\square$ S denotes subjective measurements: $\mathrm{S} 1$ includes perceived air quality, odour intensity, thermal comfort, health symptoms and sleepiness; S2 indicates self-estimation of performance; S3 indicates perceived air quality and odour intensity

$\mathrm{T}$ denotes test battery: $\mathrm{T} 1$ is test typing; $\mathrm{T} 2$ is proof-reading; $\mathrm{T} 3$ is neurobehavioural tests; $\mathrm{T} 4 \mathrm{a}$ is addition while $\mathrm{T} 4 \mathrm{~b}$ is subtraction; $\mathrm{T} 5$ is $\mathrm{d} 2$ test and Tsai-Partington test

Fig. 1 Experimental procedure

\section{Experimental procedure}

Twenty-five subjects were exposed in groups of five to all five exposure conditions, using a Latin square design to balance the order of presentation of the exposure conditions. Each group participated in the experiments for 1 week, from Monday to Friday. The subjects took part in a practice and instruction session on the Friday or Thursday prior to the week in which their exposures took place. During the experiments, the subjects wore the same type of garment throughout (with a mean thermal insulation estimated to be 0.75 clo on average) to remain thermally neutral during each exposure. The garments were selected by the subjects themselves during the practice and instruction session.

Each experimental session started in the afternoon at 13:00 and ended by 18:00 (Figure 1). Each exposure in the chamber lasted $255 \mathrm{~min}$ and was divided into two identical blocks with a short break between. In each block, subjects performed multiple tasks and made subjective evaluations as indicated earlier; several physiological data were also monitored (Figure 1). Prior to and after the exposure in the chamber, the physiological measurements were carried out. The experiment ended after the subjects re-entered the chamber to make final assessments of the air quality and odor intensity as a 'visitor'. The detailed procedure is illustrated in Figure 1 and was also described by Zhang et al. (2016).
Statistical analysis

Measures of central tendency and variance were obtained for all parameters after the raw data had been checked manually for gross errors and outliers. All statistical analyses were within-subjects comparisons; that is, responses of the same subject were compared with each other rather than comparing responses between different subjects.

For parameters measured prior to and after exposure, including blood pressure, forced expiration, nasal peak flow, and salivary biomarkers, the differences were determined by subtracting the levels measured after and prior to exposure in the chamber. A paired $t$ test was used to determine whether these differences differed significantly from zero; the 2-Tail significance level was set to 0.05 .

The parameters measured four times (respiration rate) or five times $\left(\mathrm{ETCO}_{2} / \mathrm{SPO}_{2}\right)$ were analyzed using a mixed ANOVA model assuming that these data were normally distributed. The subsequent validation of the model for each outcome showed no strong evidence invalidating this assumption. Exposure conditions (c), time at which measurements were performed during the day ( $\mathrm{t}$ ), interaction between condition and time (ct), order of exposure of conditions (o), and gender of the subjects $(\mathrm{g})$ were considered as fixed factors, while subjects (S), groups ( $\mathrm{Gr}$ ), interaction between subjects and conditions (SC) and between subjects and time (ST) were considered as random factors. The sig- 
nificance level was set to 0.05 for the fixed factors and to 0.1 for the random factors. As these data were collected repeatedly for several times at specific moments during the day, time was included as a fixed factor and not as a covariate. The analyses were made with an open source $\mathrm{R}$ package lmerTest, which can automatically investigate and incorporate the necessary factors by sequentially removing non-significant terms in the mixed model (Kuznetsova et al., 2015). Post hoc analyses were performed using a paired $t$-test in an attempt to compare differences between different exposure conditions at the same time points during each exposure.

In addition to the above parameters, which were measured intermittently, there was also a continuous measurement of heart rate during each exposure. Heart rate measured when subjects performed text typing, addition, and redirection test was analyzed. The reason for selecting these periods was that performance of the addition task and the redirection test was significantly affected by exposure conditions (Zhang et al., 2016) and that the respiration rate was also monitored during the typing task, so that any effects on cardiovascular functions and respiratory functions could be examined simultaneously. Heart rate was analyzed using a statistical model similar to the one described above: The average heart rate of each subject was calculated for the different time periods indicated above at each exposure condition and used as input values in the statistical models.

\section{Results}

All results are based on the measurements for all 25 subjects participating in the experiments except for the data for $\mathrm{ETCO}_{2}$ and blood pressure, which were only available for 20 subjects; measurements made on five subjects were missing due to instrument failure. Average and standard error for all parameters measured are tabulated in the supplementary material available online (Tables S1-S3). This section presents the main findings for those outcomes, for which the differences between exposure conditions were statistically signifi- cant. Physical measurements show that the measured conditions and the intended conditions (Table 3) were similar: Air temperature was $23.9 \pm 0.2^{\circ} \mathrm{C}$; relative humidity was $29.5 \pm 4.4 \%$; lighting intensity was $378 \pm 73$ lux; and noise level was $48 \pm 0.5 \mathrm{~dB}(\mathrm{~A})$. Measured $\mathrm{CO}_{2}$ concentration as shown in Table 3 was slightly higher than expected at M3000 (by about 4-6\%). Ozone concentrations were $22 \pm 13 \mathrm{ppb}, 24 \pm$ $21 \mathrm{ppb}, 23 \pm 15 \mathrm{ppb}, 15 \pm 3 \mathrm{ppb}$, and $3 \pm 2 \mathrm{ppb}$ for B500, P1000, P3000, M1000, and M3000, respectively. The ozone level was slightly higher when the outdoor air supply rates were high, as would be expected, that is, during exposures termed B500, P1000, and P3000. No measurements of outdoor ozone levels were performed, but the measurements from the nearest station monitoring ambient air pollution levels show that outdoor ozone levels were about 30-36 ppb during the entire experiment. As no measurement of ozone was taken immediately after the air handling unit, it is difficult to estimate how much ozone was scavenged in the ventilation system itself. The ozone concentrations measured at B500, $\mathrm{P} 1000$, and P3000, when the air change rate was high, suggest that this loss was not negligible.

Figure 2 (left) shows that $\mathrm{ETCO}_{2}$ increased significantly compared with the pre-exposure level independently of the exposure conditions and stabilized after about the first two hours of exposure (shaded area). Figure 2 (left) also shows that when $\mathrm{ETCO}_{2}$ reached a 'plateau' and was no longer increasing, levels of $\mathrm{ETCO}_{2}$ were systematically higher during exposures to bioeffluents (M1000 and M3000) and to added $\mathrm{CO}_{2}$ at the level of $3000 \mathrm{ppm}$ (P3000) compared with B500, although the differences were small. $\mathrm{ETCO}_{2}$ levels from $117 \mathrm{~min}$ to $234 \mathrm{~min}$ were averaged and are shown in Figure 2 (right). The figure shows that the average levels of $\mathrm{ETCO}_{2}$ for P3000, M1000, and M3000 were significantly higher than at B500. This suggests that these exposures could influence gas exchange in the lungs.

There were no differences between exposure conditions in respiration rate as measured with thermistors.
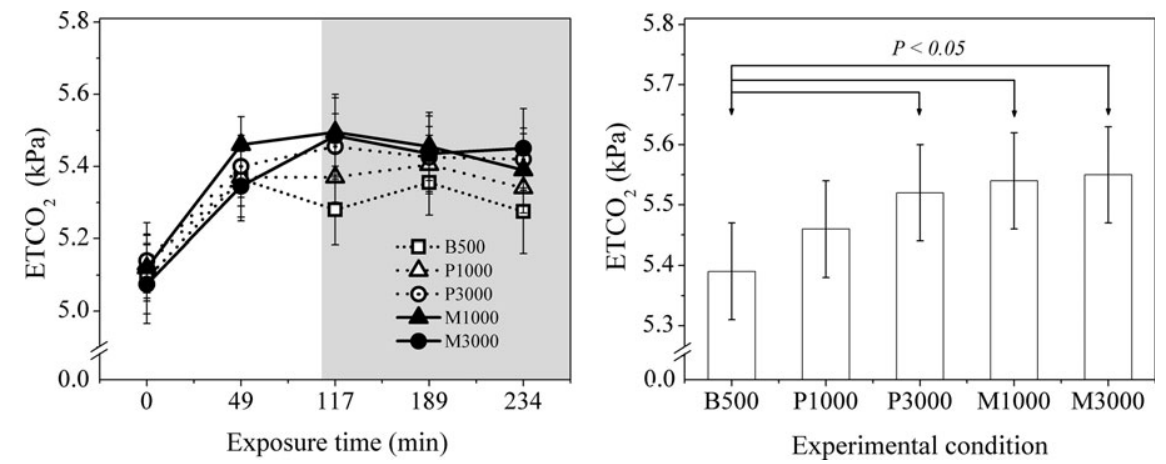

Fig. 2 Change of $\mathrm{ETCO}_{2}$ along the course of exposure (left) and average of $\mathrm{ETCO}_{2}$ during the period from 117 min to 234 min when $\mathrm{ETCO}_{2}$ was no longer changing in each condition (right); the error bars show standard error 


\section{Zhang et al.}

Nasal peak flow decreased after exposure to $\mathrm{CO}_{2}$ at 3000 ppm both when pure $\mathrm{CO}_{2}$ was added (P3000) and when ventilation rate was restricted to increase the level of $\mathrm{CO}_{2}$ and bioeffluents (M3000) compared with the pre-exposure levels (Figure 3), but the reduction was statistically significant only for the latter exposure (M3000).

No effects on intrapulmonary obstruction as measured with a Spirometry test were observed.

Figure 4 (left) shows that heart rate decreased significantly during the first two hours of exposure, independently of the exposure conditions, and remained unchanged thereafter (shaded area, 128-245 min). Figure 4 (right) shows additionally that during this period (when heart rate had reached a 'plateau' and was no longer decreasing), average heart rate was significantly higher during exposures to $\mathrm{CO}_{2}$ at $3000 \mathrm{ppm}$ when pure $\mathrm{CO}_{2}$ was added (P3000) and when ventilation rate was restricted to increase the level of $\mathrm{CO}_{2}$ and bioeffluents (M3000) when compared to B500.

Diastolic blood pressure increased after the exposure compared with the pre-exposure level in all conditions: The increase after exposure to $\mathrm{CO}_{2}$ at $3000 \mathrm{ppm}$ when ventilation rate was restricted to increase the level of

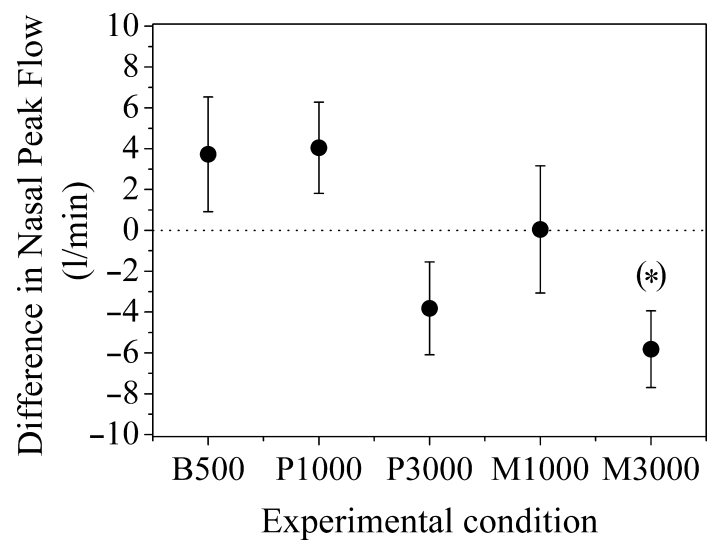

Fig. 3 Difference in nasal peak flow between the levels after and before exposure (negative value indicates a decrease from the pre-exposure level); $(*)$ shows the difference was statistically significant; bars show standard error

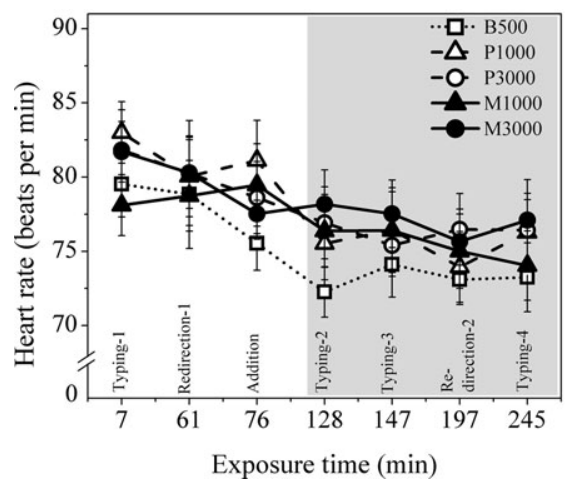

$\mathrm{CO}_{2}$ and bioeffluents (M3000) was statistically significant (Figure 5).

$\mathrm{SPO}_{2}$ increased significantly over the course of exposure independently of conditions but no significant differences between exposure conditions were observed.

After $4.5 \mathrm{~h}$ of exposure, the levels of biomarkers in saliva were different from those measured immediately prior to exposure: $\alpha$-amylase increased, while cortisol levels decreased independently of exposure conditions (Figure 6). The observed change of these two biomarkers follows the natural diurnal changes: Cortisol levels are high in the morning and fall as the day proceeds, while the opposite change occurs for $\alpha$-amylase (Nater et al., 2007). The measured levels of these two biomarkers before and after exposure were all within the normal range of $60-240 \mathrm{U} / \mathrm{ml}$ for $\alpha$-amylase, and 3-24 nmol/1 for cortisol (Table S3). Figure 6 suggests that exposure to $\mathrm{CO}_{2}$ at $1000 \mathrm{ppm}$ and $3000 \mathrm{ppm}$ when ventilation rate was restricted (M1000 and M3000) increased $\alpha$-amylase more than would be expected as a result of the diurnal rhythm and compared to what was seen in the other three exposures (B500, P1000, and P3000).

\section{Discussion}

Exposures to $\mathrm{CO}_{2}$ at 3000 ppm when pure $\mathrm{CO}_{2}$ was added caused the $\mathrm{ETCO}_{2}$ to increase to a higher level and heart rate to decrease less than in the reference exposure in which the $\mathrm{CO}_{2}$ concentration was $500 \mathrm{ppm}$. No other physiological reactions were observed during exposure to added $\mathrm{CO}_{2}$ at levels below $3000 \mathrm{ppm}$. This is generally consistent with previous work (Table 1), which essentially did not show any physiological reactions at levels lower than $5000 \mathrm{ppm}$. High $\mathrm{CO}_{2}$ could be expected to increase the respiration rate, as this would be a natural defense mechanism that ensured that acid-base homeostasis in blood remains unaffected. However, no difference in respiration rate was measured during exposures to the $\mathrm{CO}_{2}$ levels examined in the present study.

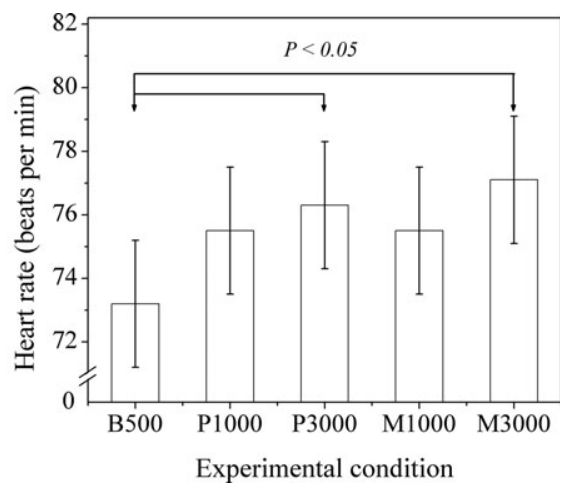

Fig. 4 Change of heart rate during the course of each exposure (left) and average of heart rate during the period from 128 to 245 min when heart rate was longer changing in each condition (right); the error bars show the standard error 
Exposures to $\mathrm{CO}_{2}$ at $3000 \mathrm{ppm}$ when ventilation rate was restricted to increase the level of $\mathrm{CO}_{2}$ and bioeffluents significantly increased diastolic blood pressure and concentrations of salivary $\alpha$-amylase, and significantly decreased heart rate and nasal peak flow. $\mathrm{ETCO}_{2}$ increased more and heart rate decreased less than in the reference exposure in which the $\mathrm{CO}_{2}$ concentration was $500 \mathrm{ppm}$. Increased $\mathrm{ETCO}_{2}$ may suggest insufficient elimination of $\mathrm{CO}_{2}$ from the body, due to lower minute ventilation as a consequence of lower tidal volume and/or respiration rate. This interpretation seems likely considering that heart rate decreased during each exposure (Figure 3), as heart rate and minute ventilation are closely related, lower heart rate being associated with lower minute ventilation (Vai et al., 1988). No measurements of tidal volume were made in the present experiment. However, as the measured respiration rate did not differ between conditions it is likely that the increased $\mathrm{ETCO}_{2}$ was due to reduced tidal volume, implying that the subjects were

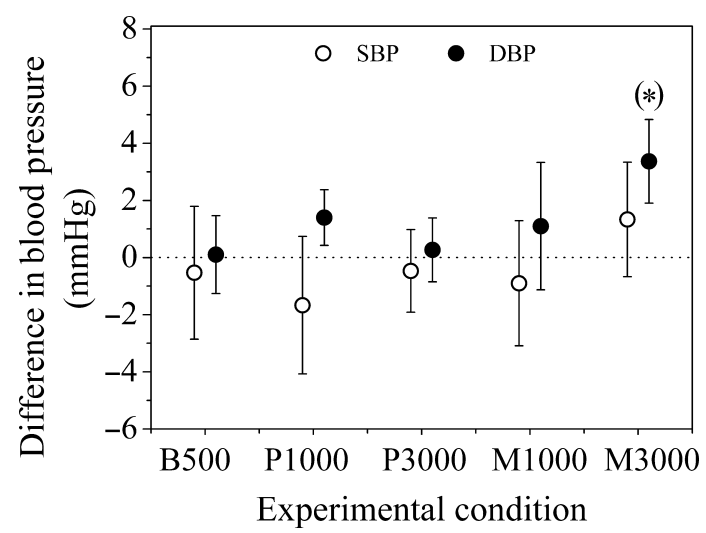

Fig. 5 Difference in systolic (SBP) and diastolic blood pressure (DBP) between the levels after and before exposure (positive value shows an increase compared to pre-exposure); (*) shows the difference was statistically significant; the error bars show the standard error

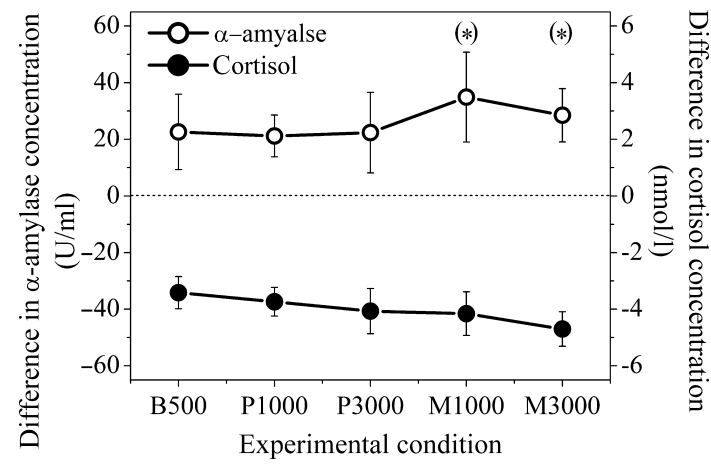

Fig. 6 Difference in concentration of $\alpha$-amylase and cortisol between the levels after and before exposure (positive value indicates an increase compared to pre-exposure level); $(*)$ shows the difference was statistically significant; the error bars show the standard error breathing more shallowly, especially during exposures when ventilation was restricted to increase the level of bioeffluents and $\mathrm{CO}_{2}$ to $3000 \mathrm{ppm}$. High $\mathrm{ETCO}_{2}$ can cause vasodilation and increased cerebral flow resulting in headaches. This mechanism has previously been suggested as a potential mechanism underlying reduced performance due to poor indoor air quality (Bakó-Biró et al., 2005). Zhang et al. (2016) who reported the other results from the present experiments showed that the intensity of headache was higher at M3000 in the present experiment, which could be partially attributed to higher $\mathrm{ETCO}_{2}$. No higher intensity of headache was reported by subjects at exposure termed P3000 when pure $\mathrm{CO}_{2}$ was added even though $\mathrm{ETCO}_{2}$ was elevated under this exposure condition.

There were no changes in respiration rate between any of the exposures. To further examine the effects of $\mathrm{CO}_{2}$ exposures on respiration rate and capture the effects during the first minutes of exposure, that is, immediately upon entering the chamber, an additional experiment was performed with a new group of subjects 1 month after the completion of the experiment described in the Methods section. Ventilation rate was set high enough to remove the human bioeffluents. High $\mathrm{CO}_{2}$ concentrations were achieved by dosing $\mathrm{CO}_{2}$ as in the present experiment. The procedure of this additional experiment is illustrated in Figure 7. Six subjects entered the chamber with the $\mathrm{CO}_{2}$ level at $400 \mathrm{ppm}$. After $5 \mathrm{~min}$, dosing of $\mathrm{CO}_{2}$ commenced and the $\mathrm{CO}_{2}$ concentration gradually increased for $15 \mathrm{~min}$ to $3000 \mathrm{ppm}$ and remained at $3000 \mathrm{ppm}$ for $10 \mathrm{~min}$. The subjects then left the chamber for $5 \mathrm{~min}$ to breathe the air with $\mathrm{CO}_{2}$ at $400 \mathrm{ppm}$ and re-entered the chamber to experience instantaneous exposure to $\mathrm{CO}_{2}$ at $3000 \mathrm{ppm}$ for $5 \mathrm{~min}$. During the whole procedure, $\mathrm{CO}_{2}$ concentration, temperature, and relative humidity were monitored continuously. Respiration rate was measured using the apparatus described in the Methods section and analyzed in the same way. No any other measurements were performed. The results of this supplementary experiment confirmed the finding

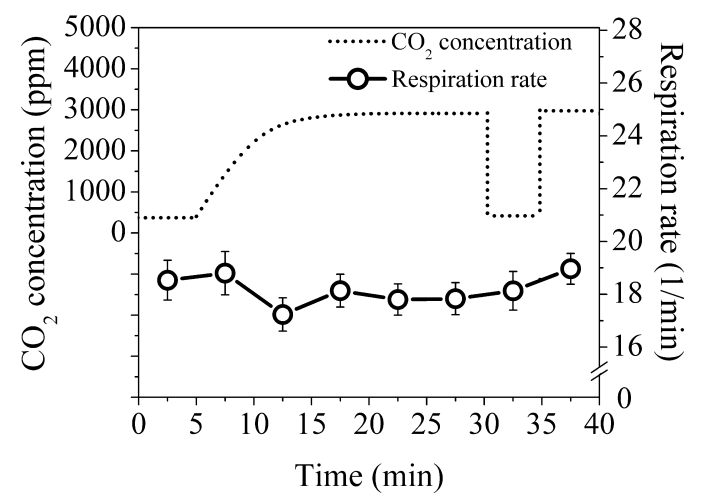

Fig. 7 Respiration rate during gradual and instantaneous exposure to high pure $\mathrm{CO}_{2}$ 
of the main experiment. Only slight fluctuations in respiration rate were observed as a response to the changes of $\mathrm{CO}_{2}$ level, as illustrated in Figure 7. No systematic differences were observed.

That no effects on respiration rate were seen is in agreement with the previous work by Stricker et al. (1997). They observed no effects on respiration rate when their subjects slept in a bedroom in which the $\mathrm{CO}_{2}$ concentration was $3000 \mathrm{ppm}$ throughout the night. High $\mathrm{CO}_{2}$ levels up to $75000 \mathrm{ppm}$ inhaled for a short time (up to $20 \mathrm{~min}$ ) could increase respiration rate when compared to air with $\mathrm{CO}_{2}$ at $300 \mathrm{ppm}$ (Bailey et al., 2005; Maresh et al., 1997), but in the present experiments the difference in $\mathrm{CO}_{2}$ levels between background and exposure condition was no more than $2500 \mathrm{ppm}$. As humans now spend most of the time indoors, their average exposure to $\mathrm{CO}_{2}$ is higher, probably 600-700 ppm. To initiate a response in respiration rate, much larger change of $\mathrm{CO}_{2}$ level would probably be needed, compared to those examined in the present experiment. Another possible explanation of why no change of respiration rate was observed is that at a low activity level people tend to mediate the minute ventilation rate by changing tidal volume rather than respiration rate (Vai et al., 1988). In the present experiment, the subjects were sedentary and were performing typical office work during the exposures, so the activity level was indeed low.

Higher diastolic blood pressure can indicate a change in the sympathetic nervous system as a consequence of higher stress/arousal. Kajtár and Herczeg (2012) observed that diastolic blood pressure increased but after exposure to added $\mathrm{CO}_{2}$ at $5000 \mathrm{ppm}$ compared with $600 \mathrm{ppm}$. Higher salivary $\alpha$-amylase in the present experiment after exposures when ventilation rate was restricted to increase $\mathrm{CO}_{2}$ and bioeffluents (M1000 and M3000) implies an increased stress (arousal) level as a result of activation of the sympathetic nervous system. That stress/arousal level was higher is also suggested by the reduced performance of the Tsai- partington test (Zhang et al., 2016). Broad attention and low arousal are needed for efficient performance of this cue-utilization test (Eysenck and Willett, 1962). In the present experiment, performance of the Tsai-Partington test was reduced (but not significantly) during exposure to added $\mathrm{CO}_{2}$ (Zhang et al., 2016), but there were no other physiological indications of increased stress/arousal. In future work, it would be useful to measure stress biomarkers repeatedly during exposure and to continuously measure stress indicators such as heart rate variability.

Decreased nasal peak flow might be due to slight inflammation, swelling, or some other adverse effects on the mucous membranes of the nasal cavity. However, subjects did not report any acute health symptoms related to the respiratory tract as reported in the companion paper describing the results of the present experiment (Zhang et al., 2016). $\mathrm{CO}_{2}$ has been shown by Abolhassani et al. (2009) to cause inflammation of the respiratory system, but only at levels up to 17 times higher (50000 ppm) than in the present experiment, so it is unlikely that the present results are due to elevated $\mathrm{CO}_{2}$ exposure.

The present results make it possible to hypothesize what mechanisms might underlie the negative effects of exposure to $\mathrm{CO}_{2}$ with bioeffluents. The hypothetical mechanisms are illustrated in Figure 8 and are compatible with the effects reported in the present paper and in the companion paper by Zhang et al. (2016), including physiological responses, subjective ratings, and effects on mental performance. The observed responses could be the combined effects of both mechanisms.

Exposures evoking physiological responses, such as elevating $\mathrm{ETCO}_{2}$ and causing vasodilation, can lead to acute health symptoms such as headaches that would be expected to reduce performance (Mechanism 1 in Figure 8). A cause-effect link of this kind was seen in the present study as subjects reported elevated intensity of headache, fatigue, sleepiness, and difficulty in thinking clearly, as reported in the companion paper by

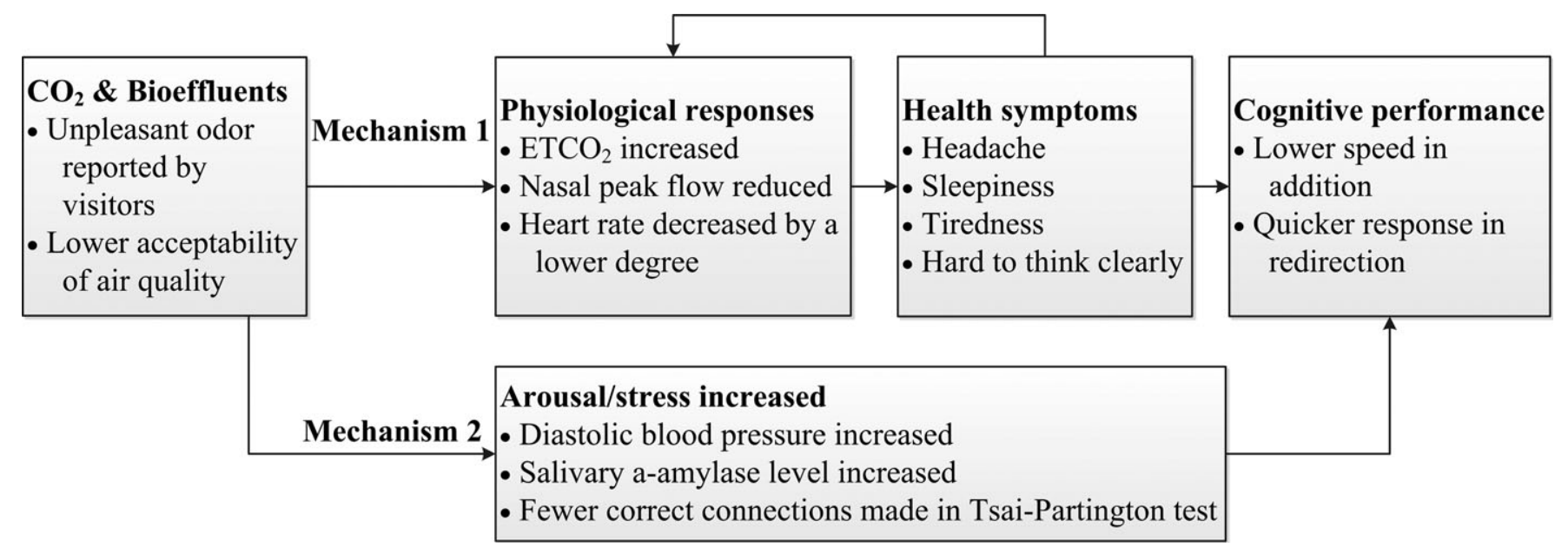

Fig. 8 Hypothetical mechanisms for the effects of exposure to $\mathrm{CO}_{2}$ with bioeffluents on cognitive performance 
Zhang et al. (2016). Meanwhile, negative effects on mental performance might also be mediated by stress (Mechanism 2 in Figure 8). Whether higher stress is induced by $\mathrm{CO}_{2}$ or other pollutants remains undetermined considering the fact that during the exposure to added $\mathrm{CO}_{2}$, there was no difference between conditions in terms of salivary $\alpha$-amylase even though performance of the Tsai-Partington test tended to decrease (non-significantly). To further advance and confirm the model evidence is needed covering the indicators related to each of the pathways depicted in Figure 8. Such information should be provided in future research.

For exposure to added $\mathrm{CO}_{2}$, no consistent explanation can be proposed on the basis of the present results. $\mathrm{ETCO}_{2}$ increased but no symptoms were reported by subjects. Performance of the Tsai-partington test was reduced but no changes in other indicators of stress were seen. It is likely that elevated stress could explain the reduced decision-making performance seen during exposure to elevated $\mathrm{CO}_{2}$ reported by Satish et al. (2012) and Allen et al. (2015), as their decision-making test requires a much higher level of cue-utilization capacity than is required for efficient performance of the tasks used in the present experiment, and its high level of cognitive demand may raise arousal in itself, but the present study does not provide credible evidence that this could be the case.

Present study intended to examine the responses of randomly selected healthy college-age adults, but it appeared to be quite difficult to recruit only subjects without atopy or any form of sensitivity. Twelve subjects indicated that they considered themselves sensitive to indoor air quality and eight to be atopic. This could be considered as a limitation of the present findings as they can be biased by responses of subjects who were more sensitive than the general population. For example, recent studies (Fadeyi et al., 2015; Tham and Fadeyi, 2015) show that atopic subjects are less sensitive to poor air quality but more easy to develop physiological-like symptoms (flu, chest tightness, and headache) compared with non-atopic subjects. To examine whether the strong bias could exist, supplementary analyses were made. In one analysis, the ratings of air quality, odor intensity, and air freshness made by subjects considering themselves sensitive to air quality $(n=12)$ were compared with the ratings of other subjects $(n=13)$ to examine whether they were different. No significant differences were observed (data not shown in the present study). In another analysis, the ratings of air quality and the measured physiological responses of atopic subjects $(n=8)$ and non-atopic subjects $(n=17)$ were compared. No difference in responses of atopic and non-atopic subjects were observed either (data not shown in the present paper). In the latter analysis, the number of atopic subjects was considerably lower than the number of non-atopic subjects. Furthermore, the order of presentation of exposures to atopic and non-atopic subjects was not balanced. As a result, comparisons between atopic and non-atopic subjects can be somewhat distorted. Nevertheless, these supplementary analyses do not provide convincing argument that the results of the present experiments were biased by inclusion of atopic subjects and subjects who considered themselves to be sensitive to air quality. Future studies should pay careful attention to the selection of subjects as this may have consequences for the observed results. The future studies should also attempt to benchmark the results of physiological measurements against the true physiological baseline. This was not intended in the present work, which focused merely on changes of physiological responses in different exposure conditions modified by adding pure $\mathrm{CO}_{2}$ or restricting ventilation rate.

\section{Conclusions}

- Exposure to $\mathrm{CO}_{2}$ at 3000 ppm when pure $\mathrm{CO}_{2}$ was added increased $\mathrm{ETCO}_{2}$ more, and decreased heart rate less than was observed to occur in the reference condition in which the $\mathrm{CO}_{2}$ concentration was $500 \mathrm{ppm}$. No other significant changes in physiological responses were seen during exposures to added $\mathrm{CO}_{2}$.

- Exposure to bioeffluents, when ventilation rate was restricted and $\mathrm{CO}_{2}$ concentration was at $1000 \mathrm{ppm}$ or $3000 \mathrm{ppm}$, increased $\mathrm{ETCO}_{2}$ and salivary $\alpha$-amylase concentration significantly more than during exposure to a $\mathrm{CO}_{2}$ level of $500 \mathrm{ppm}$. Exposure to bioeffluents, when ventilation rate was restricted and $\mathrm{CO}_{2}$ concentration was at $3000 \mathrm{ppm}$, significantly increased diastolic blood pressure and reduced nasal peak flow compared with pre-exposure levels. It also decreased heart rate significantly less than during exposure to $\mathrm{CO}_{2}$ at $500 \mathrm{ppm}$. No other significant physiological changes were seen during exposures to $\mathrm{CO}_{2}$ with bioeffluents.

- The present results suggest that exposure to human bioeffluents when metabolically generated $\mathrm{CO}_{2}$ is at $3000 \mathrm{ppm}$ may elevate arousal/stress or lead to physiological effects that cause health symptoms and either mechanism would be expected to reduce cognitive performance. There was no clear indication that such effects might occur as a result of exposure to pure $\mathrm{CO}_{2}$. Further research on this issue is needed.

\section{Acknowledgements}

This work is supported by the Bjarne Saxhof Foundation in Denmark and by the Key Program of the National Natural Science Foundation of China (51238005). Thanks are due to Shu Yuan for assistance during the experiments. Claus Nordstrøm from the 
Danish Centre for Environment and Energy provided the urban monitoring data for ozone and our DTU colleague David Wyon provided extensive comments on the manuscript.

\section{Supporting Information}

Additional Supporting Information may be found in the online version of this article:
Table S1. Measures of cardiovascular function during the exposures (Mean \pm s.e.).

Table S2. Measures of respiratory function during the exposures (Mean \pm s.e.).

Table S3. Measures of stress biomarkers during the exposures (Mean \pm s.e.).

\section{References}

Abolhassani, M., Guais, A., Chaumet-Riffaud, P., Sasco, A.J. and Schwartz, L. (2009) Carbon dioxide inhalation causes pulmonary inflammation, Am. $J$. Physiol.-Lung C., 296, L657-L665.

ACGIH (2011) Documentation of the Threshold Limit Values and Biological Exposure Indices, Cincinnati, American Conference of Governmental Industrial Hygienists.

Albrechtsen, O. (1988) Twin climatic chambers to study sick and healthy buildings. In: Proceedings of Healthy Buildings '88, Vol 3, pp. 25-30.

Allen, J.G., Macnaughton, P., Satish, U., Santanam, S., Vallarino, J. and Spengler, J.D. (2015) Associations of cognitive function scores with carbon dioxide, ventilation, and volatile organic compound exposures in office workers: a controlled exposure study of green and conventional office environments, Environ. Health Perspect., doi: 10.1289/ehp.1510037.

Apte, M.G., Fisk, W.J. and Daisey, J.M. (2000) Associations between indoor $\mathrm{CO}_{2}$ concentrations and sick building syndrome symptoms in U.S. office buildings: an analysis of the 1994-1996 BASE study data, Indoor Air, 10, 246-257.

Bailey, J.E., Argyropoulos, S.V., Kendrick, A.H. and Nutt, D.J. (2005) Behavioral and cardiovascular effects of $7.5 \% \mathrm{CO}_{2}$ in human volunteers, Depress. Anxiety, 21, 18-25.

Bakó-Biró, Z.S., Wargocki, P., Wyon, D.P. and Fanger, P.O. (2005) Poor indoor air quality slows down metabolic rate of office workers. In: Proceedings of Indoor Air 2005, Vol 1, pp. 76-80.

Bekö, G., Lund, T., Nors, F., Toftum, J.R. and Clausen, G. (2010) Ventilation rates in the bedrooms of 500 Danish children, Build. Environ., 45, 2289-2295.

Darling, E.K., Cros, C.J., Wargocki, P., Kolarik, J., Morrison, G.C. and Corsi, R.L. (2012) Impacts of a clay plaster on indoor air quality assessed using chemical and sensory measurements, Build. Environ., 57, 370-376.

Diaper, A., Nutt, D.J., Munafò, M.R., White, J.L., Farmer, E.W. and Bailey, J.E. (2012) The effects of $7.5 \%$ carbon dioxide inhalation on task performance in healthy volunteers, J. Psychopharmacol., 26, 487-496.

Erdmann, C.A., Steiner, K.C. and Apte, M.G. (2002) Indoor Carbon Dioxide Concentrations and Sick Building Syndrome Symptoms in the Base Study Revisted: Analyses of the 100 Building Dataset, Lawrence Berkeley National Laboratory.

Eysenck, H.J. and Willett, R.A. (1962) Cue utilization as a function of drive: an experimental study, Percept. Mot. Skills, 15, 229-230.

Fadeyi, M.O., Tham, K.W. and Wu, W.Y. (2015) Impact of asthma, exposure period, and filters on human responses during exposures to ozone and its initiated chemistry products, Indoor Air, 25, 512 522.

Fang, L., Clausen, G. and Fanger, P.O. (1998a) Impact of temperature and humidity on perception of indoor air quality during immediate and longer whole-body exposures, Indoor Air, $\mathbf{8}$, 276-284.

Fang, L., Clausen, G. and Fanger, P.O. (1998b) Impact of temperature and humidity on the perception of indoor air quality, Indoor Air, 8, 80-90.

Fanger, P.O. (1988) Introduction of the olf and the decipol units to quantify air pollution perceived by human indoors and outdoors, Energ. Buildings, 12, 1-6.

Gortner, D.A., Messier, A.A., Heyder, E. and Schaefer, K.E. (1971) The Effects of Elevated Atmospheric $\mathrm{CO}_{2}$ on Acid-Base Balance and Red-Cell Electrolytes of FBM Submarine Crew Members, Naval Submarine Medical Center.

Haverinen-Shaughnessy, U., Moschandreas, D.J. and Shaughnessy, R.J. (2011) Association between substandard classroom ventilation rates and students' academic achievement, Indoor Air, 21, 121-131.

James, J.T., Meyers, V.E., Sipes, W., Scully, R.R. and Matty, C.M. (2011) Crew health and performance improvements with reduced carbon dioxide levels and the resource impact to accomplish those reductions. In: Proceedings of AIAA 41st International Conference on Environmental Systems, pp. 5047-5052.
Kajtár, L. and Herczeg, L. (2012) Influence of carbon-dioxide concentration on human well-being and intensity of mental work, Q. J. Hung. Meteorol. Serv., 116, 145-169.

Kjærgaard, S., Hauschildt, P., Pejtersen, J. and Mølhave, L. (1999) Human exposure to emissions from building materials. In: Proceedings of the 8th International Conference on Indoor Air Quality and Climate, pp. 507512.

Kuznetsova, A., Christensen, R.H.B., Bavay, C. and Brockhoff, P.B. (2015) Automated mixed ANOVA modeling of sensory and consumer data, Food Qual. Prefer., 40, 31-38.

Law, J., Watkins, S. and Alexander, D. (2010) In Flight Carbon Dioxide Exposures and Related Symptoms: Association, Susceptibility, and Operational Implications, Houston, NASA Johnson Space Center.

Law, J., Van Baalen, M., Foy, M., Mason, S.S., Mendez, C., Wear, M.L. and Alexander, D. (2014) Relationship between carbon dioxide levels and reported headaches on the international space station, J. Occup. Environ. Med., 56, 477-483.

Maddalena, R., Mendell, M.J., Eliseeva, K., Chan, W.R., Sullivan, D.P., Russell, M., Satish, U. and Fisk, W.J. (2015) Effects of ventilation rate per person and per floor area on perceived air quality, sick building syndrome symptoms, and decision-making, Indoor Air, 25, 362-370.

Maresh, C.M., Armstrong, L.E., Kavouras, S.A., Allen, G.J., Casa, D.J., Whittlesey, M. and Lagasse, K.E. (1997) Physiological and psychological effects associated with high carbon dioxide levels in healthy men, Aviat. Space Environ. Med., 68, 4145.

Masoli, M., Fabian, D., Holt, S. and Beasley, R. (2004) The global burden of asthma: executive summary of the GINA Dissemination Committee report, Allergy, 59, 469-478.

Menå, H. and Larsen, E. (2010) Indoor Environment in Schools. Master, Technical University of Denmark. 


\section{Physiological responses during $\mathrm{CO}_{2}$ exposure}

Mendell, M.J., Eliseeva, E.A., Davies, M.M., Spears, M., Lobscheid, A., Fisk, W.J. and Apte, M.G. (2013) Association of classroom ventilation with reduced illness absence: a prospective study in California elementary schools, Indoor Air, 23, 515-528.

Myhrvold, A.N., Olsen, E. and Lauridsen, Ø. (1996) Indoor environment in schools-pupils health and performance in regard to $\mathrm{CO}_{2}$ concentrations. In: Proceedings of Indoor Air '96, Vol 1, pp. 369-374.

Nater, U.M., Rohleder, N., Schlotz, W., Ehlert, U. and Kirschbaum, C. (2007) Determinants of the diurnal course of salivary alpha-amylase, Psychoneuroendocrinology, 34, 392-401.

Pettenkofer, M.V. (1858) Über den Luftwechsel in Wohngebäuden, München, Cotta'schenbuchhandlung.

Satish, U., Mendell, M.J., Shekhar, K., Hotchi, T., Sullivan, D., Streufert, S. and Fisk, W.J. (2012) Is $\mathrm{CO}_{2}$ an indoor pollutant? Direct effects of lowto-moderate $\mathrm{CO}_{2}$ concentrations on human decision-making performance, Environ. Health Perspect., 120, 16711705.

Sayers, J.A., Smith, R.E.A., Holland, R.L. and Keatinge, W.R. (1987) Effects of carbon dioxide on mental performance, J. Appl. Physiol., 63, 25-30.
Schaefer, K.E., Hastings, B.J., Carey, C.R. and Nichols, G. (1963) Respiratory acclimatization to carbon dioxide, J. Appl. Physiol., 18, 1071-1078.

Sechzer, P.H., Egbert, L.D., Linde, H.W., Cooper, D.Y., Dripps, R.D. and Price, H.L. (1960) Effect of $\mathrm{CO}_{2}$ inhalation on arterial pressure, ECG and plasma catecholamines and $17-\mathrm{OH}$ corticosteroids in normal man, J. Appl. Physiol., 15, 454458.

Seppänen, O.A., Fisk, W.J. and Mendell, M.J. (1999) Association of ventilation rates and $\mathrm{CO}_{2}$ concentrations with health and other responses in commercial and institutional buildings, Indoor Air, 9, 226-252.

Shaughnessy, R.J., Haverinen-Shaughnessy, U., Nevalainen, A. and Moschandreas, D. (2006) A preliminary study on the association between ventilation rates in classrooms and student performance, Indoor Air, 16, 465-468.

Sliwka, U., Krasney, J.A., Simon, S.G., Schmidt, P. and Noth, J. (1998) Effects of sustained low-level elevations of carbon dioxide on cerebral blood flow and autoregulation of the intracerebral arteries in humans, Aviat. Space Environ. Med., 69, 299-306.

Stricker, S., Bourgeau, M., Fconberg, E. and Pdarent, D. (1997) Physiological responses to elevated carbon dioxide levels in buildings, Indoor Built Environ., 6, 301-308.

Tham, K.W. and Fadeyi, M.O. (2015)

Towards whom should indoor environmental quality control be sympathetic-Asthmatics or non-asthmatics? Build. Environ., 88, 55-64.

Vai, F., Bonnet, J.L., Ritter, P. and Pioger, G. (1988) Relationship between heart rate and minute ventilation, tidal volume and respiratory rate during brief and low level exercise, Pacing Clin. Electrophysiol., 11, 1860-1865.

Vehviläinen, T., Lindholm, H., Rintamäki, H., Pääkkönen, R., Hirvonen, A., Niemi, O. and Vinha, J. (2016) High indoor $\mathrm{CO}_{2}$ concentrations in an office environment increases the transcutaneous $\mathrm{CO}_{2}$ level and sleepiness during cognitive work, J. Occup. Environ. Hyg., 13, 19-29.

Woods, S.W., Charney, D.S., Goodman, W.K. and Heninger, G.R. (1988) Carbon dioxide-induced anxiety: behavioral, physiologic, and biochemical effects of carbon dioxide in patients with panic disorders and healthy subjects, Arch. Gen. Psychiatry, 45, 43-52.

Zhang, X.J., Wargocki, P. and Lian, Z.W. (2016) Effects of exposure to carbon dioxide and bioeffluents on perceived air quality, self-assessed acute health symptoms, and cognitive performance, Indoor Air, doi: 10.1111/ina.12284. 